\title{
Xenopus development from late gastrulation to feeding tadpole in simulated microgravity
}

\author{
WENDY M. OLSON*, DARRELL J. WIENS, THERESA L. GAUL, \\ MANUELA RODRIGUEZ and CHÉRIE L. HAUPTMEIER \\ Department of Biology, University of Northern lowa, IA, USA
}

\begin{abstract}
Microgravity $(\mu \mathrm{G})$ is known to influence cytoskeletal structure, but its effects on cell migration are not well understood. To examine the effects of altered gravity on neural crest cell (NCC) migration, we inserted Xenopus laevis embryos into two separate $\mu \mathrm{G}$-simulating slow turning lateral vessels (STLVs) just before neurulation (stage 11-12), and exposed them until feeding stage (stage 45), when the jaws and branchial apparatus are fully functional. To evaluate apparatus-related artifacts, we used two different STLVs and a vibration control as well as a stationary control vessel. Larval growth, pattern of NCC-derived cartilage formation, and incidence of malformations were analyzed using immunolocalization and wholemount staining of cartilage with Alcian blue. Interestingly, the two STLVs often yielded different or conflicting results. Many differences, such as increased cartilage size, attenuated Hoxa2 expression, and increased cell division, may be attributed mainly to vibration of the rotating vessels. However, tadpoles that developed in simulated microgravity (both STLVs, but not the vibration control) showed significantly more skeletal abnormalities, with stronger effects on cartilages derived from NCCs than those derived mainly from mesoderm. We conclude that migrating NCCs of Xenopus are sensitive to the altered gravitational environment of STLVs, and that studies relying on bioreactors to simulate microgravity also need to take variation in apparatus into account.
\end{abstract}

KEY WORDS: neural crest, visceral skeleton, microgravity, STLV, Xenopus

\section{Introduction}

During the past two decades, Xenopus laevis (the African clawed frog) has been used as a model system to study the effects of altered gravity on development. Embryos raised in space from fertilization to free-living tadpole stage show characteristic differences compared to earth-bound or on-board centrifuged $1 \mathrm{G}$ control embryos, but the differences have been largely inconsequential (Souza et al., 1995; Black et al., 1996; De Maziere et al., 1996). Tadpoles of normal appearance emerge despite some alterations in cleavage, gastrulation, and neurulation. Both swimming behavior and optomotor response were sometimes altered in the tadpoles raised in $\mu \mathrm{G}$, but tadpoles would normalize upon return to normal gravity (Souza et al., 1995; Fejtek et al., 1998). Other studies involving exposure to spaceflight $\mu \mathrm{G}$ during development in Xenopus have found alterations in the development of the vestibular apparatus (Souza et al., 1994; Pronych et al., 1996) and vestibuloocular reflex (Sebastian and Horn, 2001; Horn, 2006).
A study of the effect of 11.5 days of spaceflight on Xenopus larvae showed considerable derangement of structure. The tadpoles, launched at the early tailbud stage (approximately one day old), exhibited caudal lordosis (also noted in a study by Horn, 2006), disproportionately long tails and short bodies, a failure to inflate their lungs, and a reduced, misshapen branchial apparatus (Snetkova et al., 1995). The acceleration and vibration of the launch and the sudden onset of $\mu \mathrm{G}$ may have caused or contributed to these irregularities. Nevertheless, large amounts of cell migration and differentiation were occurring during this time. If the process of cell migration is sensitive to gravitational cues, possibly mediated through the cytoskeleton (Ingber, 1999), then this stage of development may be especially vulnerable to exposure

Abbreviations used in this paper: $\mathrm{BrdU}$, bromodeoxyuridine; $\mathrm{CB}$, ceratobranchial; CDHA, cartilage-defined head area; CH, ceratohyal; IR, infrarostrals; MeC, Meckel's cartilage; $\mu \mathrm{G}$, microgravity; NCC, neural crest cell; Noto, notochord; STAT, stationary control; STLV, slow turning lateral vessel; VIBR, vibration control.

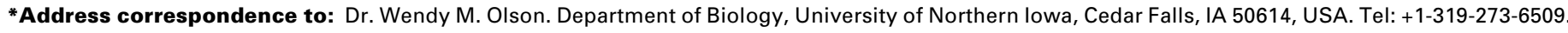
Fax: +1-319-273-7125. e-mail: wendy.olson@uni.edu
} 
to altered gravity.

Exposure of early anuran embryos to $\mu \mathrm{G}$ simulated through rotation in a clinostat or a rotating wall vessel (bioreactor) produces results quite similar to those in spaceflight: detectable and statistically significant changes in cleavage, blastula morphology, and gastrulation. Again, these are regulated upon return to normal gravity, resulting in largely normal tadpoles (Neff et al., 1993; Chung et al., 1994). Exposure to hypergravity (non-damaging level) through centrifugation produces changes that are sometimes opposite in orientation or direction to those produced by $\mu \mathrm{G}$. For example, whereas microgravity may yield tadpoles with larger heads and eyes, hypergravity may induce microcephaly, microphthalmia, increased apoptosis, and suppressed gene expression (Neff et al., 1993; Yokota et al., 1994; Kawakami et al., 2006). In both cases, self-correcting developmental regulation may occur.

Parallel studies have been performed using zebrafish embryos, which like Xenopus are small and hardy enough to be raised inside the chamber of a clinostat or bioreactor. Exposure of early zebrafish to simulated $\mu \mathrm{G}$ resulted in elevated expression of $\beta$-actin and heat shock proteins (Moorman, 2003; Shimada and Moorman, 2006). Susceptibility to altered gravity varied by organ and developmental stage, with prolonged exposure (over three days) resulting in a return to normal expression patterns in most tissues (Shimada et al., 2005). Effects on the vestibuloocular reflex have also been found in zebrafish (Moorman et al., 2002). And in a preliminary report, Cole et al. (2003) described several abnormalities in the embryonic fish Rivulus marmoratus that resulted from culture in a rotating wall vessel from fertilization until hatching. These included axial skeletal curvatures, eye defects, reduced brain ventricle volume and absence of some neural aggregations, cranial depression, and elongated mandible.

The development of the vertebrate head is an astonishingly complex process. Neural crest cells (NCCs) play a key role in the development of the skull and visceral skeleton. These highly migratory cells are derived from the neural ectoderm early in development, during the formation of the neural tube. NCCs migrate along specific pathways in the developing embryo to give

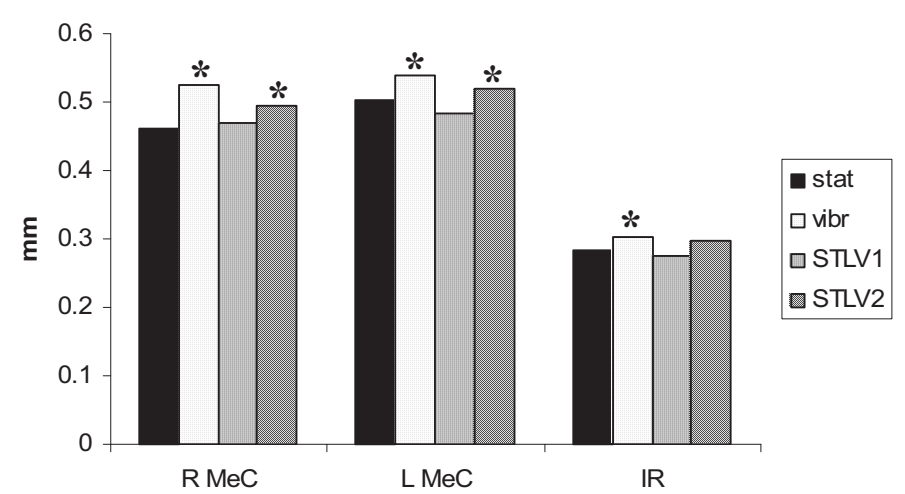

rise to a wide range of specialized tissues, including bone, cartilage, teeth, nervous tissue, and pigment cells (Hall, 1999). Cranial NCCs emerge from the anterior lateral neural folds and as they advance, form swellings in the lateral cranial regions. Responding to a succession of molecular signals, they migrate out to form three distinct streams: the mandibular, hyoid, and branchial (Noden, 1983; Sadaghiani and Thiebaud, 1987; Koentges and Lumsden, 1996; Olsson and Hanken, 1996). In Xenopus, the anteriormost (mandibular) stream migrates around the optic vesicle, and its cells differentiate and give rise to skeletal derivatives of the first visceral arch, which include the palatoquadrate, the supra- and infrarostrals, and Meckel's cartilage. The second (hyoid) stream gives rise to second arch derivatives, the paired ceratohyals, and the posterior branchial stream subdivides and gives rise to the four paired ceratobranchial (gill) arches. Interference with NCC migration in Xenopus, such as through ablation of premigratory NCCs or injection of antisense slug RNA, results in loss or abnormal development of NCC-derived visceral arch structures (Seufert and Hall, 1990; Carl et al., 1999).

Numerous recent studies have confirmed striking effects of exposure to spaceflight or simulated $\mu \mathrm{G}$ on the cytoskeleton (reviewed by Hughes-Fulford, 2002; Crawford-Young, 2006). Microtubules appear to have difficulty self-organizing in microgravity, although the presence of vibration (from launch conditions or clinostat motor) may attenuate this effect (Papaseit et al. 2000; Glade et al., 2006). Changes in overall cytoskeletal architecture, cell shape, cell locomotion, and gene expression have also been observed in a variety of cell cultures (Tjandrawinata et al., 1997; Uva et al., 2002; Meloni et al., 2006). Interestingly, at least two of these studies report acclimation and a return to almost normal function within 24-32 hours of exposure to microgravity (Uva et al., 2002; Meloni et al., 2006).

Although the exact mechanism of cellular mechanosensation remains unclear, the cytoskeleton is thought to play a central role (Ingber, 1999; Geiger and Bershadsky, 2001, 2002; Ingber, 2006). Disturbances in the organization of the cytoskeleton or its intra- and extracellular connections may underlie, at least in part, the mechanism of gravity sensitivity in cells (Ingber, 1999). Given

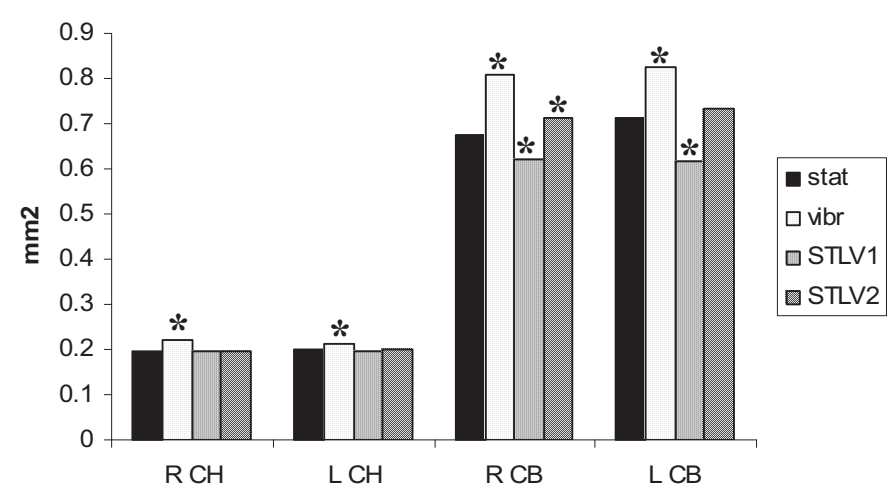

Fig. 1 (Left). Length measurements ( $\mathbf{m m}$ ) of the right and left Meckel's cartilages (MeC) and paired infrarostrals (IR). Elements were measured in ventral view. ${ }^{*}$ indicates statistically significant difference from stationary control (STAT). Elements in the vibration control (VIBR) are significantly longer than all other groups; STLV-2 elements are significantly longer than those of STLV-1. Means and standard deviations are shown in Table 1.

Fig. 2 (Right). Two-dimensional area measurements ( $\mathbf{m m 2}$ ) of the right and left ceratohyals (CH) and ceratobranchial baskets (CB). Elements were measured in ventral view. ${ }^{*}$ indicates statistically significant difference from stationary control (STAT). As with length measurements, elements in the vibration control (VIBR) are significantly larger than all other groups. The ceratobranchial baskets of STLV-2 tadpoles were significantly larger than those of STLV-1 tadpoles. Means and standard deviations are shown in Table 1. 
the importance of the cytoskeleton during cell migration, cells undergoing active migration may be more greatly affected by altered gravity than non-migrating cells. Neural crest cells migrating through the embryonic head tissues, if exposed to altered gravity through the majority of their critical formative period, may be disrupted. Abnormality or asymmetry should thus be more prevalent in NCC-derived tissues, compared to tissues not derived from NCCs.

Amphibian embryos are small enough to be exposed to altered gravity easily. To examine the effects of altered gravity on NCC migration and differentiation, we inserted Xenopus laevis embryos into two separate $\mu \mathrm{G}$-simulating slow turning lateral vessels (STLVs) just before neurulation (stage 11-12), and exposed them until feeding stage (stage 45), about five days, when the jaws and branchial apparatus are fully functional. Larval growth, incidence of malformations, pattern of head cartilage formation, and Hoxa2 expression were analyzed using antibody localization, specific staining of cartilage with Alcian blue, and in situ hybridization.

\section{Results}

There were no consistent, statistically significant differences in total length or snout-vent length among groups. On average, mortality (over 4 days) was highest in STLV-1 (18.5\%), followed by the stationary control (14.5\%), STLV-2 (14\%), and then the vibration control (12.8\%). In all treatments, most of the mortality occurred in the first two days. Later mortality coinciding with gross abnormality was highest in the two STLV groups.

\section{Meristics}

Intensity of Alcian blue staining did not vary significantly within experimental runs. Visceral arch cartilage measurements from four complete experimental runs were analyzed separately and as grouped data. As trends were consistent, only the grouped data are shown (Table 1; Figs. 1 and 2). Cartilages in the vibration control group were statistically significantly longer (length) or larger (area) than in all other groups, with a single exception: there was no significant difference between the infrarostrals of the vibration control and STLV-2 groups. Compared to those of the stationary

Fig. 3. Wholemount cartilage stained Xenopus laevis tadpoles (stage 45) from the STLV-2, showing both normal (A) and abnormal (B-D) skeletal development. (A,B), Dorsal view; (C,D), ventral view. Anterior is to the top. (B), overdevelopment of anterior structures off the left parachordal with a gap off the right parachordal (arrowhead). (B) and $(\mathbf{C})$ show asymmetrical defects; (D) is largely symmetrical. The ceratobranchial baskets of (B-D) are slightly shorter, more spherical in outline than normal (A), and the individual ceratobranchial arches appear thicker, misshapen, possibly with a less finely developed filter apparatus. The infrarostral abnormality shown in (D), leading to sharply angled Meckel's cartilages, was very common and was often coupled with simplification of the ceratohyals. Loss of individual eyes in (B$D)$ was an artifact of the staining procedure. cb, ceratobranchial basket; ch, ceratohyals; ir, infrarostrals; $m$, Meckel's cartilage; $n$, notochord; $p$, parachordal. Scale bar in A, $0.5 \mathrm{~mm}$. controls, the Meckel's cartilages and right ceratobranchials were longer or larger in the STLV-2 group, whereas the ceratobranchials (both sides) were smaller in the STLV-1 group. The Meckel's cartilages, infrarostrals, and ceratobranchials of tadpoles in the STLV-2 group were statistically significantly longer or larger than those in STLV-1. In all groups, the cartilage-defined head area showed the same trend as the ceratobranchials. With one exception (noted above), left and right elements showed the same trend. There were no significant differences in the width of the notochord, across groups.

In the vertical control experiment, cartilages of tadpoles in the vibration control and both STLV groups were longer or larger than those of the stationary control (Table 2). Unlike the simulated microgravity condition, many cartilages in the STLV-2 tadpoles were often smaller than those in the STLV-1 and vibration groups, though some were still larger than those of the stationary control. There were also some significant differences in the width of the notochord, which were not found in the simulated microgravity condition.

\section{Skeletal abnormalities}

The frequency of gross structural abnormality was greatest in the two STLV groups, followed by the vibration and then stationary control groups (Table 3 ). Fig. 3 shows examples of some of the abnormalities observed in the head skeleton. There was no consistent pattern of abnormalities, that is, no group was characterized by a particular set of deformities. For all groups, mesodermal skeletal elements (parachordals, basihyal, basibranchial, notochord) were rarely or minimally affected. Elements derived from neural crest cells (trabeculae, ethmoid plate, palatoquadrates, Meckel's cartilages, ceratohyals and ceratobranchials) were more strongly affected. Both symmetrical and asymmetrical defects
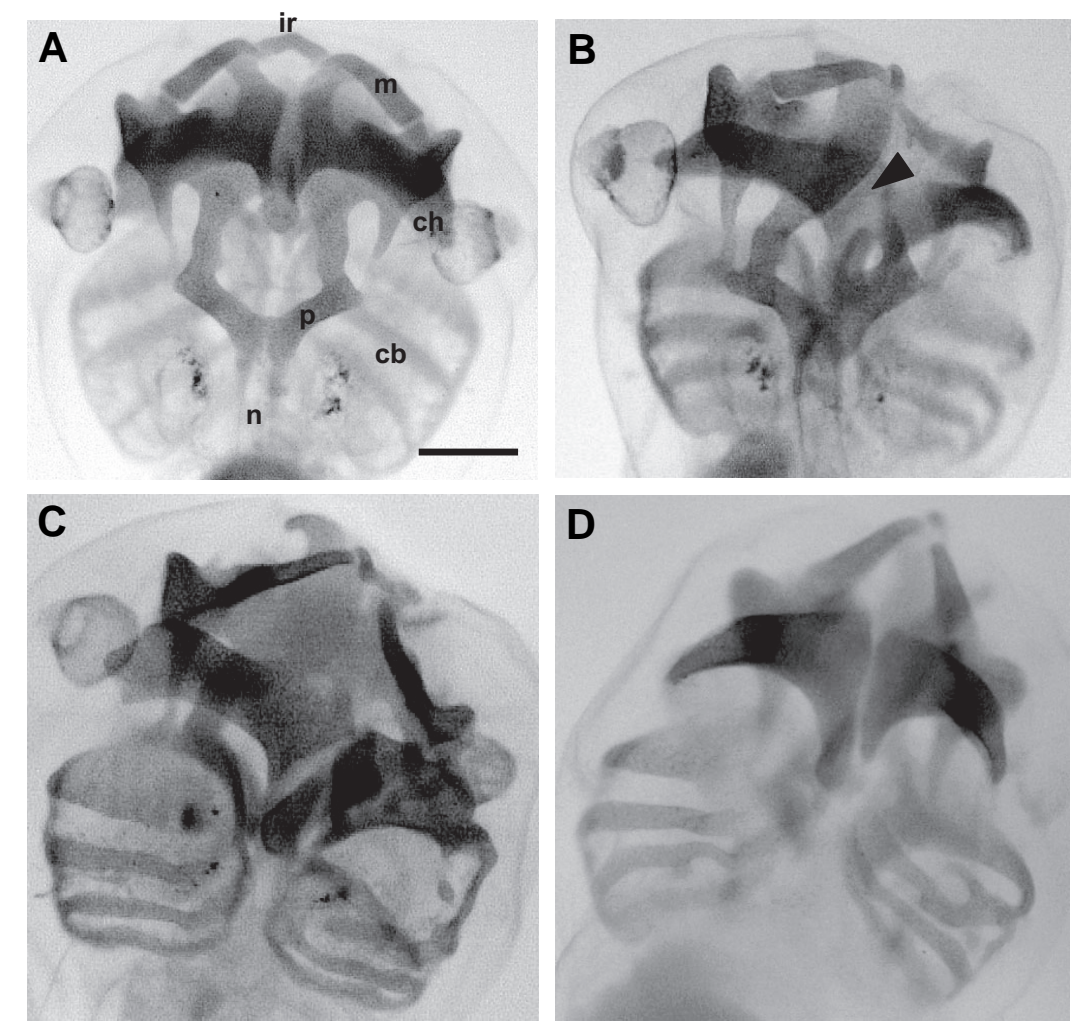
TABLE 1

MERISTICS FOR CARTILAGES OF THE HEAD SKELETON, GROUPED DATA

\begin{tabular}{|c|c|c|c|c|c|c|c|c|c|c|}
\hline & & \multicolumn{4}{|c|}{ length $(\mathrm{mm})$} & \multicolumn{5}{|c|}{ area $\left(\mathrm{mm}^{2}\right)$} \\
\hline & & $\mathrm{RMeC}$ & LMeC & IR & Noto & $\mathrm{RCH}$ & $\mathrm{LCH}$ & RCB & LCB & CDHA \\
\hline $\begin{array}{l}\text { STAT } \\
(n=101)\end{array}$ & $\begin{array}{c}x \\
\text { SD }\end{array}$ & $\begin{array}{l}0.461 \\
0.052\end{array}$ & $\begin{array}{l}0.502 \\
0.054\end{array}$ & $\begin{array}{l}0.282 \\
0.049\end{array}$ & $\begin{array}{l}0.184 \\
0.024\end{array}$ & $\begin{array}{l}0.196 \\
0.033\end{array}$ & $\begin{array}{l}0.202 \\
0.034\end{array}$ & $\begin{array}{l}0.676 \\
0.127\end{array}$ & $\begin{array}{l}0.714 \\
0.137\end{array}$ & $\begin{array}{l}2.535 \\
0.358\end{array}$ \\
\hline $\begin{array}{l}\text { VIBR } \\
(n=123)\end{array}$ & $\begin{array}{c}x \\
\text { SD }\end{array}$ & $\begin{array}{l}0.525^{*} \\
0.083\end{array}$ & $\begin{array}{l}0.540^{*} \\
0.075\end{array}$ & $\begin{array}{l}0.304^{*} \\
0.059\end{array}$ & $\begin{array}{l}0.190 \\
0.031\end{array}$ & $\begin{array}{l}0.220^{*} \\
0.043\end{array}$ & $\begin{array}{c}0.214^{*} \\
0.048\end{array}$ & $\begin{array}{l}0.809^{*} \\
0.174\end{array}$ & $\begin{array}{c}0.826^{\star} \\
0.180\end{array}$ & $\begin{array}{c}2.902^{*} \\
0.489\end{array}$ \\
\hline $\begin{array}{l}\text { STLV-1 } \\
(n=100)\end{array}$ & $\begin{array}{c}x \\
\text { SD }\end{array}$ & $\begin{array}{l}0.469^{\dagger} \\
0.074\end{array}$ & $\begin{array}{l}0.484^{\dagger} \\
0.072\end{array}$ & $\begin{array}{l}0.275^{\dagger} \\
0.070\end{array}$ & $\begin{array}{l}0.186 \\
0.030\end{array}$ & $\begin{array}{l}0.196^{\dagger} \\
0.039\end{array}$ & $\begin{array}{l}0.194^{\dagger} \\
0.040\end{array}$ & $\begin{array}{c}0.620^{*^{\dagger}} \\
0.191\end{array}$ & $\begin{array}{c}0.618^{\star^{\dagger}} \\
0.214\end{array}$ & $\begin{array}{c}2.373^{\star \dagger} \\
0.596\end{array}$ \\
\hline $\begin{array}{l}\text { STLV-2 } \\
(\mathrm{n}=117)\end{array}$ & $\begin{array}{c}x \\
\text { SD }\end{array}$ & $\begin{array}{c}0.493^{{ }^{\dagger}} \\
0.073\end{array}$ & $\begin{array}{c}0.518^{{ }^{\dagger}} \\
0.071\end{array}$ & $\begin{array}{l}0.297 \\
0.057\end{array}$ & $\begin{array}{l}0.189 \\
0.026\end{array}$ & $\begin{array}{l}0.195^{\dagger} \\
0.040\end{array}$ & $\begin{array}{l}0.199^{\dagger} \\
0.040\end{array}$ & $\begin{array}{c}0.711^{\star^{\dagger}} \\
0.140\end{array}$ & $\begin{array}{c}0.732^{\dagger} \\
0.149\end{array}$ & $\begin{array}{c}2.638^{* \dagger} \\
0.403\end{array}$ \\
\hline
\end{tabular}

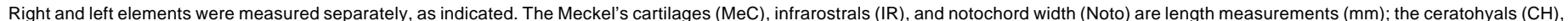

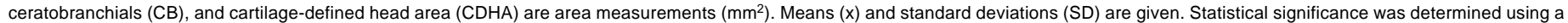

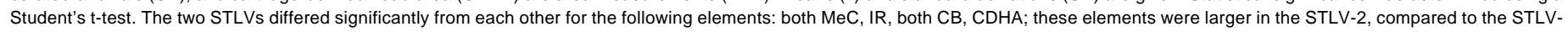
1. STAT = stationary control; VIBR $=$ vibration control. ${ }^{*}$ significant compared to stationary control $(\mathrm{p}<0.05) .{ }^{\dagger}$ significant compared to vibration control $(\mathrm{p}<0.05)$

TABLE 2

MERISTICS FOR CARTILAGES OF THE HEAD SKELETON, VERTICAL CONTROL EXPERIMENT

\begin{tabular}{|c|c|c|c|c|c|c|c|c|c|c|}
\hline & \multicolumn{4}{|c|}{ length $(\mathrm{mm})$} & \multicolumn{5}{|c|}{ area $\left(\mathrm{mm}^{2}\right)$} \\
\hline & & $\mathrm{RMeC}$ & LMeC & IR & Noto & $\mathrm{RCH}$ & LCH & $\mathrm{RCB}$ & LCB & CDHA \\
\hline $\begin{array}{l}\text { STAT } \\
(n=31)\end{array}$ & $\begin{array}{c}x \\
S D\end{array}$ & $\begin{array}{l}0.429 \\
0.055\end{array}$ & $\begin{array}{l}0.422 \\
0.052\end{array}$ & $\begin{array}{l}0.249 \\
0.051\end{array}$ & $\begin{array}{l}0.142 \\
0.020\end{array}$ & $\begin{array}{l}0.179 \\
0.027\end{array}$ & $\begin{array}{l}0.180 \\
0.032\end{array}$ & $\begin{array}{l}0.643 \\
0.165\end{array}$ & $\begin{array}{l}0.614 \\
0.127\end{array}$ & $\begin{array}{l}2.456 \\
0.390\end{array}$ \\
\hline $\begin{array}{l}\text { VIBR } \\
(n=33)\end{array}$ & $\begin{array}{c}x \\
\text { SD }\end{array}$ & $\begin{array}{l}0.462^{*} \\
0.066\end{array}$ & $\begin{array}{l}0.458^{*} \\
0.053\end{array}$ & $\begin{array}{l}0.280^{*} \\
0.048\end{array}$ & $\begin{array}{l}0.161^{*} \\
0.023\end{array}$ & $\begin{array}{l}0.221^{*} \\
0.044\end{array}$ & $\begin{array}{l}0.207^{\star} \\
0.050\end{array}$ & $\begin{array}{c}0.819^{*} \\
0.162\end{array}$ & $\begin{array}{c}0.805^{*} \\
0.156\end{array}$ & $\begin{array}{c}2.974^{*} \\
0.510\end{array}$ \\
\hline $\begin{array}{l}\text { STLV-1 } \\
(n=32)\end{array}$ & $\begin{array}{c}x \\
\text { SD }\end{array}$ & $\begin{array}{l}0.460 \\
0.072\end{array}$ & $\begin{array}{c}0.489^{*} \\
0.071\end{array}$ & $\begin{array}{l}0.274 \\
0.049\end{array}$ & $\begin{array}{c}0.158^{*} \\
0.022\end{array}$ & $\begin{array}{c}0.239^{*} \\
0.061\end{array}$ & $\begin{array}{c}0.232^{*} \\
0.056\end{array}$ & $\begin{array}{c}0.795^{\star} \\
0.205\end{array}$ & $\begin{array}{c}0.775^{*} \\
0.196\end{array}$ & $\begin{array}{c}2.925^{*} \\
0.626\end{array}$ \\
\hline $\begin{array}{l}\text { STLV-2 } \\
(n=34)\end{array}$ & $\begin{array}{c}x \\
S D\end{array}$ & $\begin{array}{l}0.428 \\
0.083\end{array}$ & $\begin{array}{c}0.456^{*} \\
0.070\end{array}$ & $\begin{array}{c}0.228^{\dagger} \\
0.040\end{array}$ & $\begin{array}{c}0.147^{\dagger} \\
0.024\end{array}$ & $\begin{array}{c}0.204^{*} \\
0.050\end{array}$ & $\begin{array}{l}0.202 \\
0.055\end{array}$ & $\begin{array}{l}0.683 \\
0.157\end{array}$ & $\begin{array}{c}0.700^{\star^{\dagger}} \\
0.176\end{array}$ & $\begin{array}{c}2.544^{\dagger} \\
0.528\end{array}$ \\
\hline
\end{tabular}

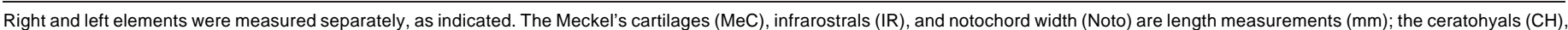

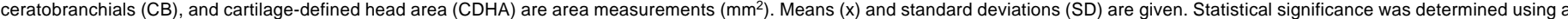

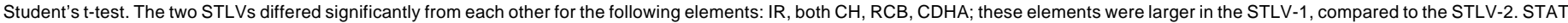
$=$ stationary control; VIBR $=$ vibration control. ${ }^{*}$ significant compared to stationary control $(p<0.05) .{ }^{\dagger}$ significant compared to vibration control $(p<0.05)$

occurred. There was no evidence of sidedness (abnormalities occurred in approximately a 1:1 left:right ratio). In the vertical control experiment, abnormalities were most common in the stationary control, followed by the STLV-1 and vibration groups, whereas tadpoles in the STLV-2 had the lowest overall incidence of abnormalities (Table 3).

\section{Size and pattern of melanocyte pigment spots}

Variability of pigment spot area was high, within clutches and among experimental conditions. We were not able to discern any consistent, statistically significant effects of simulated microgravity on pigmentation pattern.

\section{Cell proliferation in neural, cartilage and muscle tissues}

Cell proliferation results shown in Table 4 represent the means from six sections of percentages calculated for four tissues visible in sections taken at the level of the eyes. Cell proliferation in the diencephalon was about $26 \%$ for all groups and showed the least variation. Cell proliferation in the other three tissues was more variable. It was lowest in the skin, about $20 \%$, but was significantly higher in the skin of STLV-2 tadpoles than in that of STLV-1 or either control group. In ceratohyal-associated muscle it was also significantly higher in the STLV-2 group, reaching a mean of $32 \%$. In NCC derived ceratohyal cartilage it reached about $37 \%$, the highest of all, and was again significantly higher than the other three groups. There were no other significant differences. Thus only culture in one of the STLVs, the one with less vibration
(STLV-2), resulted in higher cell proliferation in three of the four tissues measured.

\section{Expression of Hoxa2}

Preliminary data on Hoxa2 expression were analyzed from a small number of specimens (3-6 specimens per experimental group). After 24 hours of exposure to simulated microgravity, Hoxa2 expression was found in the hindbrain region, in visceral arch streams, and faintly in segmental stripes along the dorsolateral region posterior to the hindbrain. The level of expression was low, somewhat variable, or even absent, but was similar in all four groups. After 48 hours of exposure, the pattern of expression had become more diffuse in the head. In the vibration control and both STLV groups, overall expression was greatly reduced, compared to the stationary control.

\section{Discussion}

Although the effects of spaceflight and simulated microgravity on amphibian development have been studied previously, there have been no studies specifically focusing on NCCs and the structures derived from them. Neural crest cells provide a substantial contribution to the cartilages of the head and visceral skeleton. Malformation or asymmetry of NCC-derived cartilages should reveal even subtle effects of environmental conditions.

In this study, Xenopus embryos were allowed to develop through the early stages in unit gravity, reaching mid to late 
gastrulation before being exposed to the vector-averaged gravity of STLV rotation. Therefore the embryos avoided early microgravity effects, establishing blastomeres, signaling centers, and germ layers with normal determination and proportion. They were then exposed throughout the period of neurulation and NCC migration for four days until they reached the feeding tadpole stage, when many NCC-derived structures must be fully functional. We found several distinct effects of the exposure during this period. Because we used two STLVs, two control vessels, and a vertical rotation control condition, we were able to sort these effects into those likely caused by simulated microgravity vs. those caused by STLV artifact, namely vibration.

Because it arises from NCCs, the epidermal pigmentation pattern of Xenopus tadpoles offers a vivid account of migration and differentiation of one NCC subpopulation. We did not find statistically significant differences among the groups in either the intensity or area of the spots. Variability of pigmentation was high within a spawned batch of embryos, and all tadpoles appeared to have an overall normal pigmentation, so if the alteration of gravity or the presence of vibration caused changes in this population of NCCs, they were minor.

We found a statistically significant increase in size of the visceral skeleton cartilages for embryos that developed in the vibration control vessel (all measured cartilages) and in the STLV2 (Meckel's cartilages and ceratobranchials). Visceral cartilages in the STLV-1 specimens were smaller than those of the vibration control, however, and the ceratobranchials were even smaller than those of the stationary control. For the vertical control experiment, embryos within the re-oriented STLVs were exposed to vibration, centripetal and shear forces, but not to vector averaged gravity. Larger cartilages were found in both STLV groups and the vibration control group, compared to the stationary control, and there were even differences in the width of the notochord. Increased size of head cartilages thus appeared to be an artifact of the vibration characteristics of the STLVs, rather than a response to simulated microgravity.

In addition, for embryos raised in the STLV-2, we found a significantly higher proportion of nuclei in S-phase of the cell cycle in ceratohyal cartilage, associated muscle, and skin, implying a higher rate of cell proliferation in these tissues. The larger size of the STLV-2 cartilages was correlated with increased cell proliferation. There were no statistical differences in cell proliferation noted in the STLV-1 (which had smaller cartilages) or the vibration control (larger cartilages). Mus limb buds cultured in a bioreactor showed differences in chondrocyte maturation, condensation size, and matrix organization (Duke and Montufar-Solis, 1999; Montufar-Solis et al., 2003). Histological sectioning of our specimens could provide more insight as to how cell size or arrangement was affected by simulated microgravity or vibration, i.e. why the individual cartilages were larger or smaller.

The two STLVs produced conflicting results, for both the meristic and BrdU data. Rotation in the STLV-1 led to smaller or normal sized cartilages and a normal cell proliferation rate. Rotation in the STLV-2 resulted in larger cartilages and a higher proliferation rate. Vibration alone seemed to have an effect on cartilage size, but it was not necessarily correlated with increased cell proliferation. The vibration control was anchored to the base of STLV-2, so those two conditions should have been exposed to similar vibration characteristics. It is well known that oxygen
TABLE 3

\section{EXPOSURE OF XENOPUS EMBRYOS TO SIMULATED MICROGRAVITY INCREASES THE INCIDENCE OF SKELETAL MALFORMATION}

\begin{tabular}{lcccc} 
& stationary control & vibration control & STLV-1 & STLV-2 \\
\hline $\mathbf{X X}$ & $2 / 58,3.4 \%$ & $0 / 64,0 \%$ & $15 / 57,26.3 \%$ & $15 / 56,26.8 \%$ \\
$\mathbf{X X I}$ & $2 / 32,6.2 \%$ & $8 / 36,22.2 \%$ & $6 / 28,21.4 \%$ & $6 / 38,15.8 \%$ \\
$\mathbf{X X I I I}$ & $3 / 43,7 \%$ & $6 / 46,13 \%$ & $7 / 40,17.5 \%$ & $6 / 39,15.4 \%$ \\
XXV & $1 / 12,8.3 \%$ & $1 / 12,8.3 \%$ & $3 / 12,25 \%$ & $2 / 11,18.2 \%$ \\
average percentage & $8 / 145, \mathbf{5 . 5} \%$ & $15 / 158,9.5 \%$ & $31 / 137,22.6 \%$ & $29 / 144, \mathbf{2 0 . 1} \%$ \\
vertical control & $6 / 31,19.3 \%$ & $3 / 33,9.1 \%$ & $4 / 32,12.5 \%$ & $5 / 34,14.7 \%$ \\
\hline
\end{tabular}

Data from four complete experimental runs are shown (XX-XXV). Similar results were not found when the STLVs were placed in a vertical position (vertical control experiment). Representative abnormalities are shown in Fig. 3.

TABLE 4

\section{CELL PROLIFERATION IN FOUR TISSUES OF EMBRYOS DEVELOPING IN STLVs OR CONTROL VESSELS}

\begin{tabular}{lcccc} 
Tissue & $\begin{array}{c}\text { Stationary } \\
\text { control }\end{array}$ & $\begin{array}{c}\text { Vibration } \\
\text { control }\end{array}$ & STLV-1 & STLV-2 \\
\hline Ceratohyal cartilage & $24.7 \pm 10.3$ & $28.5 \pm 7.6$ & $25.5 \pm 14.4$ & $36.7 \pm 5.8^{*}$ \\
Hyoid muscle & $25.1 \pm 8.16$ & $26.9 \pm 9.0$ & $23.0 \pm 9.9$ & $31.5 \pm 4.0^{*}$ \\
Skin & $19.0 \pm 4.8$ & $18.3 \pm 9.3$ & $21.0 \pm 12.7$ & $26.2 \pm 7.0^{*}$ \\
Diencenphalon & $25.0 \pm 4.8$ & $26.5 \pm 6.9$ & $25.9 \pm 5.8$ & $26.2 \pm 6.5$ \\
\hline
\end{tabular}

Embryos were exposed to BrdU during the final 40 minutes of the 5-day experiment. The data are the mean percent $\mathrm{BrdU}$-positive nuclei of total nuclei seen in sections. Each value represents six sections taken from three embryos of each group. ${ }^{*}$ significant compared to stationary control $(p<0.05)$. STLV, slow-turning lateral vessel.

concentration and especially temperature can influence developmental rate and growth, but these conditions were carefully checked for all experiments. Oxygen concentration varied only slightly. Temperature was not typically higher in the STLV-2 than in the other vessels. Temperature did tend to measure slightly higher in the vibration control vessel, but the difference was $1^{\circ} \mathrm{C}$ or less. The differences between the STLVs could have been random in nature, or possibly due to unique physical characteristics of the individual machines. A precise assessment of forces generated by the STLVs may help identify apparatus-specific artifacts.

We also found that the expression of the determinative visceral arch transcription factor Hoxa2 may be reduced by 48 hours in all groups except in the stationary control. Preliminary results thus suggest that vibration, rather than simulated microgravity, may have caused an earlier attenuation of Hoxa2. This effect is likely an artifact of the STLVs. But it does suggest that gene expression is sensitive to mechanical stimulation, and it gives support to cytoskeletal mechanotransduction hypotheses (Ingber, 1997; Geiger and Bershadsky, 2002).

Thus there appeared to be no effect of simulated microgravity on pigmentation pattern, and differences in cartilage size, cell proliferation, and Hoxa2 expression were most easily attributed to vibration. However, the altered gravity environment of the STLVs did appear to increase the incidence and severity of skeletal malformations. Skeletal abnormalities were most common in the two STLVs, moderate in the vibration control, and least common in the stationary control. Skeletal elements primarily derived from NCCs appeared to be more severely and commonly affected than those derived primarily from mesoderm, suggesting a possible 
disruption in NCC migration or subsequent differentiation. Although NCC derived elements make up more of the head skeleton and are thus more readily observed than mesodermal elements, we found that the only mesodermal element measured, the notochord, did not vary significantly among groups. We did not observe many of the spaceflight microgravity effects noted by Snetkova et al. (1995), such as significant differences in body or tail length, caudal lordosis, or changes in notochord size and shape. But we did observe similar effects on the branchial basket, notably a more spherical shape and possibly less development of the gill filters. Interestingly, frequency of skeletal malformation dropped in the STLVs when they were reoriented to rotate along the vertical axis, thus exposing embryos to shear and vibration, but not vector-averaged gravitational forces.

This study provides evidence that when Xenopus embryos are exposed to simulated microgravity during a period of peak NCC migration and differentiation, the probability of disruption of proper development of the head skeleton increases. It also clearly illustrates that different STLVs have different vibrational characteristics and may effect slightly different outcomes. Studies relying on bioreactors to simulate microgravity need to take mechanical variation in apparatus into account. We conclude that the migrating NCCs of Xenopus that create the intricate, functioning head skeleton are sensitive to the altered gravitational environment of STLVs.

\section{Materials and Methods}

Embryos and culture conditions in the slow turning lateral vessel Adult pairs of frogs were injected with human chorionic gonadotropin to induce spawning, according to established protocols (Sive et al., 1994). Embryos were dejellied using 2\% cysteine and were collected for culture beginning at late gastrulation, stage 11-12 (Nieuwkoop and Faber, 1967). They were cultured as stationary controls in a loose-lidded (allowing air exchange) $250 \mathrm{ml}$ glass jar placed on a lab bench. A control for vibrations generated by the motor within the instrument was achieved with another $250 \mathrm{ml}$ jar placed on a large rubber stopper near and attached to an STLV rotator base (Synthecon, Inc., Houston, TX) with tape to equalize vibration as nearly as possible. Each STLV measured $11 \mathrm{~cm}$ in length, $5.5 \mathrm{~cm}$ total diameter, and $1.75 \mathrm{~cm}$ from core to internal wall. The STLV has an aeration membrane covering its core that can be pressurized with an air pump to maintain oxygen concentration. However, the pump creates considerably more vibration, so all experiments were conducted with the air pump disabled. Experimental embryos were cultured simultaneously in two $250 \mathrm{ml} \mathrm{STLV} \mathrm{units,} \mathrm{each} \mathrm{with} \mathrm{its} \mathrm{own} \mathrm{rotator} \mathrm{base} \mathrm{and} \mathrm{power} \mathrm{supply,}$ in order to control for variation in the vibration characteristics. Viewed by high-speed video, the vibrations generated by the motor in the instrument rotator base showed no detectable displacement of embryos. Recording with a 20 centimeter microphone placed five $\mathrm{cm}$ from the upper edge of the rotator amplified a humming noise with major peaks at 60 hertz with minor harmonic peaks. This characteristic AC hum came from the electric motors, and was more intense from STLV-1 than STLV-2.

All four sterilized vessels were filled with $250 \mathrm{ml}$ of aerated, sterile $10 \%$ Steinberg's solution and embryos were pipetted in. Within experimental runs, all embryos were from the same clutch. The density of embryos present in each of the vessels within a given experimental run ranged from 16 to 75 ( 1 embryo/15.62 $\mathrm{ml}$ to 1 embryo/3.33 $\mathrm{ml}$ ), depending on the size of the clutch; density did not appear to affect subsequent body dimensions, temperature or oxygen concentration. Bubbles were expelled with syringes attached to the ports of the STLVs, which were then attached to the rotator base. The instruments were turned on and the speed was adjusted until the embryos achieved freefall in an elliptical orbit, at about
27 revolutions per minute. To achieve an additional control condition (vertical control), one experiment was carried out with the rotator base turned on its side so that the rotation axis was vertical rather than horizontal. In this condition all factors except freefall suspension in liquid and simulated $\mu \mathrm{G}$ were identical.

All vessels were on a stable lab bench in a room with a steady $22^{\circ} \mathrm{C}$ temperature and approximately 12 hour light cycle for five days, at which time the tadpoles had reached stage 45 (Nieuwkoop and Faber, 1967). To prevent growth of microorganisms and maintain oxygen levels rotation was stopped briefly, and the $10 \%$ Steinberg's solution was replaced after two and four days of rotation. Any dead embryos were removed at this time. There were no obvious differences in hatching time. Activity levels were not explicitly quantified, but appeared to vary the most in the vibration control group; tadpoles in the vibration control went through a stage of almost constant swimming, but by the end of the experiment, were hardly moving at all. During the solution changes and at the end of the experiments oxygen levels were found to be $6.0-7.8 \mathrm{mg} / \mathrm{L}$ with none of the four vessels consistently different from the others. The temperatures in the vessels were within $0.5^{\circ}$ of $22.6^{\circ} \mathrm{C}$, with the exception of the vibration control, which was usually within $0.1^{\circ}$ of $23.4^{\circ} \mathrm{C}$

\section{Staining of cartilage and assessment of cartilage and body dimen- sions}

At the end of the experiments, all embryos were fixed in $4 \%$ paraformaldehyde or $10 \%$ neutral buffered formalin and photographed. Snout-vent length and total length were measured from the photographs. Specimens were then stained for cartilage with Alcian Blue using standard procedures (Klymkowsky and Hanken, 1991; Olson, 2000). The stained embryos were examined with a Leica M16 stereomicroscope and images were taken from the ventral side using an Optronics MagnaFire or Leica DFC 480 digital camera. Body and individual cartilage dimensions were measured and analyzed using either Openlab (Improvision, Inc.) or Image-Pro (Media Cybernetics, Inc.) software. The Meckel's cartilages, infrarostrals, ceratohyals, ceratobranchial baskets, and cartilage-defined head area (ventral outline of the cartilaginous portions of the skull and visceral skeleton) were measured as either maximum lengths or areas. The width of the notochord was measured at the posterior border of the ceratobranchial baskets. The notochord was chosen as a non-NCC derived skeletal element that had been described in previous microgravity studies in Xenopus (e.g. Snetkova et al., 1995). Specimens were also assessed individually for skeletal abnormalities. As this was highly qualitative (specimens had to be very obviously malformed to be counted), one individual assessed all specimens, blind to condition. Counts were checked randomly by a second individual. As an approximate measure of chondrogenesis, Alcian Blue staining intensity was evaluated with $\mathrm{NIH}$ Image software (written by Wayne Rasband, U.S. National Institutes of Health, available at http://rsb.info.nih.gov/nih-image/Default.html).

\section{In situ hybridization analysis of Hoxa2 expression}

The transcription factor Hoxa2 is thought to play a role in specification of second (hyoid) visceral arch fate (Rijli et al., 1993; Lumsden and Krumlauf, 1996; Grammatopoulos et al., 2000; Trainor and Krumlauf, 2000; Baltzinger et al., 2005). A PCS2 plasmid containing the Xenopus homologue for Hoxa2 was a gift from Filippo M. Rijli (Pasqualetti et al., 2000). Whole mount in situ hybridization and analysis of Hoxa2 expression was carried out on embryos 24 and 48 hours after onset of the experiments. The embryos were fixed in $4 \%$ paraformaldehyde and then hybridized with sense and antisense digoxygenin-UTP RNA probes (Roche) synthesized from linearized templates using the T7 RNA polymerase. Single probe hybridizations were done as described in Sive et al. (1994). After probe detection, embryos were mounted and photographed.

\section{Assessment of cell proliferation}

During the final 45 minutes of the experiment, rotation was stopped and bromodeoxyuridine (BrdU) was added from a stock solution to $7.5 \mu \mathrm{g} /$ 
$\mathrm{ml}$. The embryos were fixed in $4 \%$ paraformaldehyde, dehydrated, embedded in paraffin, sectioned at $5 \mu \mathrm{m}$, deparaffinized in xylene, rehydrated, and immunostained with biotinylated anti-BrdU and counterstained with hematoxylin using a Zymed BrdU staining kit (Zymed Laboratories Inc., S. San Francisco, CA). The number of stained nuclei as a percentage of the number of total nuclei was determined for ceratohyal cartilage, ceratohyal-associated muscle, brain (diencephalon), and skin, from 6 sections per embryo. Counting of nuclei was done without knowledge of identity. Differences in the percentages were compared using single factor analysis of variance and, if significantly different, with student's T-Tests and Bonferroni's correction. Probabilities of less than $5 \%$ were considered significant.

\section{Assessment of skin pigmentation}

One population of NCCs takes a dorsolateral migration route and eventually enters the epidermis to differentiate as skin melanocytes. These create a characteristic pattern of brown-black pigment spots, which are apparent in stage 45 tadpoles. We used image analysis to determine whether simulated microgravity altered the total area or mean intensity of these spots. Lateral images of the stage 45 tadpoles were first converted into black and white $\mathrm{NIH}$ Image files, and the region from rostrum to vent was selected. After processing to find the edges of all spots, the selection was thresholded at the program default level. The eye and outer boundary were then erased, and the areas and intensities of the spots were analyzed as particles to yield areas and intensities (on a scale of $0-255$ ), which were summed and averaged, respectively. The means of 10-12 tadpoles' total spot areas and average intensities in the four treatment groups were compared using single factor analysis of variance and, if significantly different, with student's T-Tests and Bonferroni's correction.

\section{Acknowledgments}

This work was supported by an lowa Space Grant Consortium Cooperative Activity grant. We thank Colleen Kahn, Melody Heber, Michelle Formanek and Chelsea Reinhard for technical assistance. We also thank Dr. Diane Slusarski and Hilary Grisbach (University of lowa) for assistance with Hoxa2 staining, and Dr. Dale Olson and Dr. Jill Trainer (University of Northern lowa) for advice on video and audio recording of the STLVs. Support for student stipends and supplies came from the Biology Department at the University of Northern lowa, and from Merck/ AAAS.

\section{References}

BALTZINGER, M., ORI, M., PASQUALETTI, M., NARDI, I. and RIJLI, F.M. (2005). Hoxa2 knockdown in Xenopus results in hyoid to mandibular homeosis. Dev. Dyn. 234: 858-867.

BLACK, S., LARKIN, K., JACQMOTTE, N., WASSERSUG, R. and SOUZA, K. (1996). Regulative development of Xenopus laevis in microgravity. Adv. Space Res. 17: 209-217.

CARL, T.F., DUFTON, C., HANKEN, J. and KLYMKOWSKY, M.W. (1999). Inhibition of neural crest migration in Xenopus using antisense Slug RNA. Dev. Biol. 213: $101-115$.

CHUNG, H.M., YOKOTA, H., DENT, A., MALACINSKI, G.M. and NEFF, A.W. (1994). The location of the third cleavage plane of Xenopus embryos partitions morphogenetic information in animal quartets. Int J. Dev. Biol. 38: 421-428.

COLE, K.S., SUNDARESAN, A., PELLIS, N. and GREEN, S.M. (2003). Abnormal development effects in Rivulus marmoratus (Teleostei) exposed to a rotating cell culture system environment during embryonic development. Grav. Space Biol. Bull 17: 57.

CRAWFORD-YOUNG, S.J. (2006). Effects of microgravity on cell cytroskeleton and embryogenesis. Int. J. Dev. Biol. 50: 183-191.

DE MAZIERE, A., GONZALEZ-JURADO, J., RIEJNEN, M., NARRAWAY, J. and UBBELS, G.A. (1996). Transient effects of microgravity on early embryos of Xenopus laevis. Adv. Space Res. 17: 219-223.
DUKE, P.J. and MONTUFAR-SOLIS, D. (1999). Exposure to altered gravity affects all stages of endochondral cartilage differentiation. Adv. Space Res. 24: 821827.

FEJTEK, M., SOUZA, K., NEFF, A. and WASSERSUG, R. (1998). Swimming kinematics and respiratory behavior of Xenopus laevis larvae raised in altered gravity. J. Exp. Biol. 201: 1917-1926.

GEIGER, B. and BERSHADSKY, A. (2001). Assembly and mechanosensory function of focal contacts. Curr. Opin. Cell Biol. 13: 584-592.

GEIGER, B. and BERSHADSKY, A. (2002). Exploring the neighborhood: adhesioncoupled cell mechanosensors. Cell 110: 139-142.

GLADE, N., BEAUGNON, E. and TABONY, J. (2006). Ground-based methods reproduce space-flight experiments and show that weak vibrations trigger microtubule self-organisation. Biophys. Chem. 121: 1-6.

GRAMMATOPOULOS, G.A., BELL, E., TOOLE, L., LUMSDEN, A. and TUCKER, A.S. (2000). Homeotic transformation of branchial arch identity after Hoxa2 overexpression. Development 127: 5355-5365.

HALL, B.K. (1999). The Neural Crest in Development and Evolution. SpringerVerlag, New York.

HORN, E.R. (2006). Microgravity-induced modifications of the vestibuloocular reflex in Xenopus laevis tadpoles are related to development and the occurrence of tail lordosis. J. Exp. Biol. 209: 2847-2858.

HUGHES-FULFORD, M. (2002). Physiological effects of microgravity on osteoblast morphology and cell biology. Adv. Space Biol. Med. 2002: 129-157.

INGBER, D.E. (1997). Tensegrity: the architectural basis of cellular mechanotransduction. Annu. Rev. Physiol. 59: 575-599.

INGBER, D.E. (1999). How cells (might) sense microgravity. FASEB J. 13: S3-S15

INGBER, D.E. (2006). Cellular mechanotransduction: putting all the pieces together again. FASEB J. 20: 811-827.

KAWAKAMI, S., KASHIWAGI, K., FURUNO, N., YAMASHITA, M. and KASHIWAGI A. (2006). Effects of hypergravity environments on amphibian development, gene expression and apoptosis. Comp. Biochem. Physiol. Part A: Molec. Integr. Physiol. 145: 65-72.

KLYMKOWSKY, M.W. and HANKEN, J. (1991). Whole-mount staining of Xenopus and other vertebrates. Methods in Cell Biology 36: 419-441.

KOENTGES, G. and LUMSDEN, A. (1996). Rhombencephalic neural crest segmentation is preserved throughout craniofacial ontogeny. Development 122 3229-3242.

LUMSDEN, A. and KRUMLAUF, R. (1996). Patterning the vertebrate neuraxis Science 274: 1109-1115.

MELONI, M.A., GALLERI, G., PIPPIA, P. and COGOLI-GREUTER, M. (2006). Cytoskeleton changes and impaired motility of monocytes at modeled low gravity. Protoplasma 229: 243-249.

MONTUFAR-SOLIS, D., OAKLEY, C.R., JEFFERSON, Y. and DUKE, P.J. (2003) Differentiation of cartilaginous anlagen in entire embryonic mouse limbs cultured in a rotating bioreactor. Adv. Space Res. 32: 1467-1472.

MOORMAN, S.J. (2003). Simulated microgravity causes changes in heat shock protein expression in zebrafish embryos. Grav. Space Biol. Bull. 17: 57.

MOORMAN, S.J., CORDOVA, R. and DAVIES, S.A. (2002). A critical period for functional vestibular development in zebrafish. Dev. Dyn. 223: 285-291.

NEFF, A.W., YOKOTA, H., CHUNG, H.M., WAKAHARA, M. and MALACINSKI, G.M. (1993). Early amphibian (anuran) morphogenesis is sensitive to novel gravitational fields. Dev. Biol. 155: 270-274.

NIEUWKOOP, P.D. and FABER, J. (1967). Normal Table of Development of Xenopus laevis (Daudin). North-Holland Publications, Amsterdam.

NODEN, D.M. (1983). The role of the neural crest in patterning of avian cranial skeletal, connective, and muscle tissues. Dev. Biol. 96: 144-165.

OLSON, W.M. (2000). Phylogeny, ontogeny, and function: extraskeletal bones in the tendons and joints of Hymenochirus boettgeri (Amphibia: Anura: Pipidae). Zoology 103: 15-24.

OLSSON, L. and HANKEN, J. (1996). Cranial neural-crest migration and chondrogenic fate in the Oriental fire-bellied toad Bombina orientalis: Defining the ancestral pattern of head development in anuran amphibians. J. Morphol. 229: 105-120.

PAPASEIT, C., POCHON, N. and TABONY, J. (2000). Microtubule self-organiza- 
tion is gravity-dependent. Proc. Natl. Acad. Sci USA 97: 8364-8368.

PASQUALETTI, M., ORI, M., NARDI, I. and RIJLI, F.M. (2000). Ectopic Hoxa2 induction after neural crest cell migration results in homeosis of jaw elements in Xenopus. Development 127: 5367-5378.

PRONYCH, S.P., SOUZA, K.A., NEFF, A.W. and WASSERSUG, R.J. (1996). Optomotor behavior in Xenopus laevis tadpoles as a measure of the effect of gravity on visual and vestibular neural integration. J. Exp. Biol. 199: 2689-2701.

RIJLI, F.M., MARK, M., LAKKARAJU, S., DIERICH, A., DOLLE, P. and CHAMBON, $P .(1993)$. A homeotic transformation is generated in the rostral branch region of the head by disruption of Hoxa-2, which acts as a selector gene. Cell75:13331349.

SADAGHIANI, B. and THIEBAUD, C.H. (1987). Neural crest development in the Xenopus laevis embryo, studied by interspecific transplantation and scanning electron microscopy. Dev. Biol. 124: 91-110.

SEBASTIAN, C. and HORN, E. (2001). Features of vestibuloocular reflex modulations induced by altered gravitational forces in tadpoles (Xenopus laevis). Adv. Space. Res. 28: 579-588.

SEUFERT, D.W. and HALL, B.K. (1990). Tissue interactions involving cranial neural crest in cartilage formation in Xenopus laevis (Daudin). Cell Diff. Dev. 32 : 153-166.

SHIMADA, N. and MOORMAN, S.J. (2006). Changes in gravitational force cause changes in gene expression in the lens of developing zebrafish. Dev. Dyn. 235: 2686-2694.

SHIMADA, N., SOKUNBI, G. and MOORMAN, S.J. (2005). Changes in gravitational force affect gene expression in developing organ systems at different develop- mental times. BMC Dev. Biol. 5: 10.

SIVE, H.L., GRAINGER, R.M. and HARLAND, R.M. (1994). Early Development of Xenopus laevis: Course Manual. Cold Spring Harbor, pp 64-74.

SNETKOVA, E., CHELNAYA, N., SEROVA, L., SAVELIEV, S., CHERDANZOVA, E., PRONYCH, S. and WASSERSUG, R. (1995). Effects of space flight on Xenopus laevis larval development. J. Exp. Zool. 273: 21-32.

SOUZA, K.A., BLACK, S.D., WASSERSUG, R.J. and ROSS, M.D. (1994). The effects of spaceflight on amphibian fertilization, development, and behavior. In Proceedings of "In Space '94." Tokyo: Japan Space Utilization Promotion Center (JSUP). pp. 113-134.

SOUZA, K.A., BLACK, S.D. and WASSERSUG, R.J. (1995). Amphibian development in the virtual absence of gravity. Proc. Natl. Acad. Sci. USA 92: 1975-1978.

TJANDRAWINATA, R.R., VINCENT, V.L. and HUGHES-FULFORD, M. (1997). Vibrational force alters mRNA expression in osteoblasts. FASEB J. 11: 493497.

TRAINOR, P.A. and KRUMLAUF, R. (2000). Patterning the cranial neural crest hindbrain segmentation and Hox gene plasticity. Nat. Rev. Neurosci. 1: 116124.

UVA, B.M., MASINI, M.A., STURLA, M.,PRATO, P.,PASSALACQUA, M., GIULIANI, M., TAGLIAFIERRO, G. and STROLLO, F. (2002). Clinorotation-induced weightlessness influences the cytoskeleton of glial cells in culture. Brain Res. 934 132-139.

YOKOTA, H., NEFF, A.W. and MALACINSKI, G.M. (1994). Early development of Xenopus embryos is affected by simulated gravity. Adv. Space Res. 14: 249 255.

\section{Further Related Reading, published previously in the Int. J. Dev. Biol.}

See our Special Issue Developmental Morphodynamics, edited by Lev Beloussov and Richard Gordon at: http://www.ijdb.ehu.es/web/contents.php?vol=50\&issue=2-3

See our Special Issue Pattern Formation, edited by Michael J. Richardson and Cheng-Ming Chuong at: http://www.ijdb.ehu.es/web/contents.php?vol=53\&issue=6-7

Msx1 and Msx2 have shared essential functions in neural crest but may be dispensable in epidermis and axis formation in Xenopus Deepak Khadka, Ting Luo and Thomas D. Sargent

Int. J. Dev. Biol. (2006) 50: 499-502

Temporal and spatial expression patterns of FoxN genes in Xenopus laevis embryos Maximilian Schuff, Antje Rössner, Cornelia Donow and Walter Knöchel Int. J. Dev. Biol. (2006) 50: 429-434

Effects of microgravity on cell cytoskeleton and embryogenesis

Susan J. Crawford-Young

Int. J. Dev. Biol. (2006) 50: 183-19

Redneck, a new mutant of the axolotl (Ambystoma mexicanum) likely affects the development of cranial neural crest S C Smith, N S Bashir and J B Armstrong Int. J. Dev. Biol. (2001) 45: 685-688

Altering the position of the first horizontal cleavage furrow of the amphibian (Xenopus) egg reduces embryonic survival H Yokota, A W Neff and G M Malacinski Int. J. Dev. Biol. (1992) 36: 527-535

Microgravity effects on the oogenesis and development of embryos of Drosophila melanogaster laid in the Spaceshuttle during the Biorack experiment (ESA) I Vernós, J González-Jurado, M Calleja and R Marco 5 yr ISI Impact Factor $(2008)=3.271$ Int. J. Dev. Biol. (1989) 33: 213-226

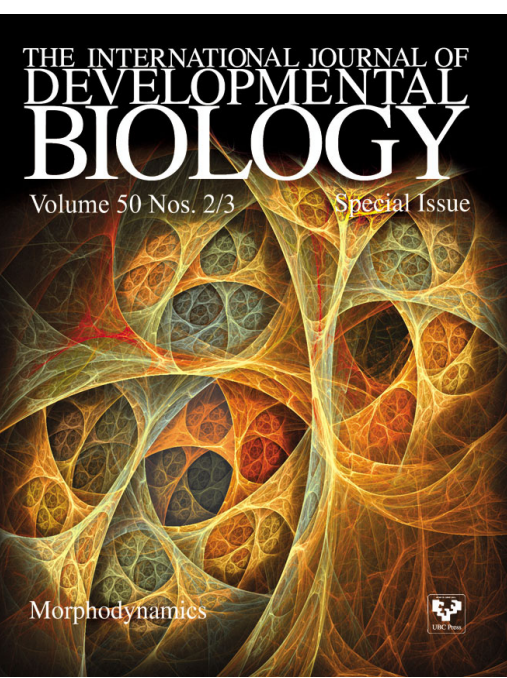

